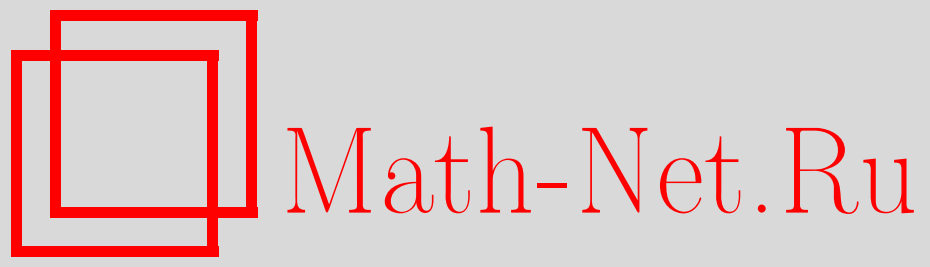

Л. Белопухов, Премия за лазерные инструменты, Квант, 2019, номер 3, 2-9

DOI: https://doi.org/10.4213/kvant20190301

Использование Общероссийского математического портала Math-Net.Ru подразумевает, что вы прочитали и согласны с пользовательским соглашением http://www.mathnet.ru/rus/agreement

Параметры загрузки:

IP : 52.6 .47 .48

26 апреля 2023 г., 13:00:07

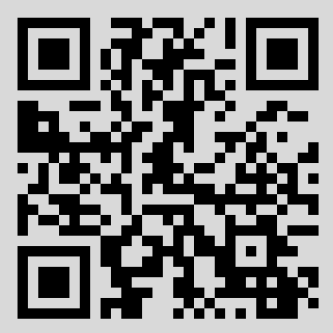




\section{Премия за лазерные инструменты}

\section{Л.БЕЛОПУХОВ}

$\mathrm{H}$ ОБЕЛЕВСКАЯ ПРЕМИЯ ПО ФИЗИКЕ 2018 года - это уже пятая премия, присужденная за изобретение и усовершенствование лазеров и их применение в разных областях науки.

Первая премия была присуждена «за фундаментальные исследования в области квантовой электроники, которые привели к созданию генераторов и усилителей нового типа - мазеров и лазеров». Лауреатами этой премии стали российские (советские) физики А.М.Прохоров и Н.Г.Басов, разделившие ее с американским физиком Ч.Таунсом. С тех пор слово «лазер» стало общеупотребительным названием очень узенького светового луча самого различного цвета. А само устройство источника этого луча уже мало кому интересно. Точно так же почти всем пользователям компьютеров и всевозможных гаджетов совсем неинтересно, что там у них внутри и как они работают.

А между тем изобретение лазеров (и мазеров) стало не только эпохальным до-

DOI: https://doi.org/10.4213/kvant20190301 стижением науки XX века. Оно блистательно утвердило квантовые представления об излучении, перевернувшие классическую физику. Недаром теоретическое обоснование лазеров было сделано великим Эйнштейном еще в 1917 году - только что миновало столетие этого события. Слова «лазер» и «мазер» еще не родились тогда. Но то, что установил Эйнштейн, «сидит» в этих названиях - это третья и четвертая буквы 3 и $e$. А в латинице это $s$ и $e$, первые буквы термина stimulated emission, введенного в квантовую физику Эйнштейном.

Им было установлено, что коллективы возбужденных частиц (прежде всего, атомов и молекул), стремясь перейти в нормальное (с минимально возможной энергией) состояние, излучают двумя способами. Один из них - когда возбужденная частица излучает независимо от наличия таких же соседних частиц. Научно выражаясь, плотность вероятности возвращения ее в нормальное состояние (т.е. вероятность в единицу времени) зависит только от свойств самой частицы (ее электрон-

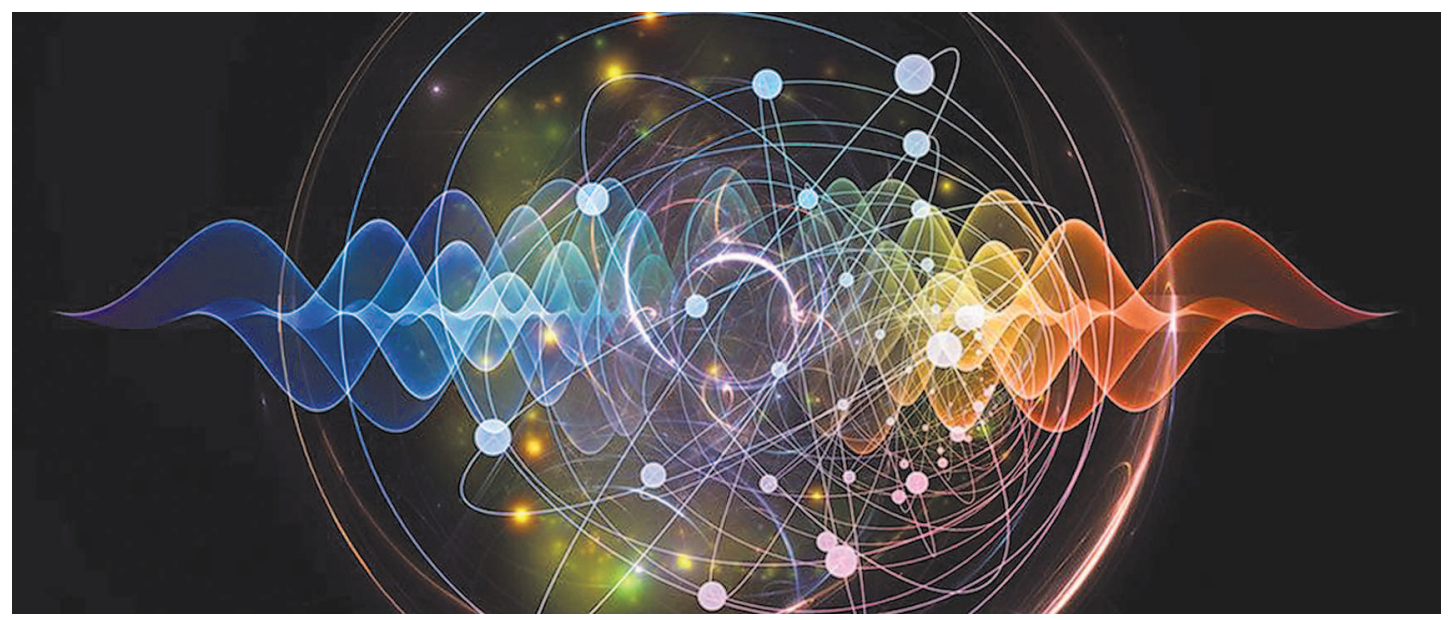




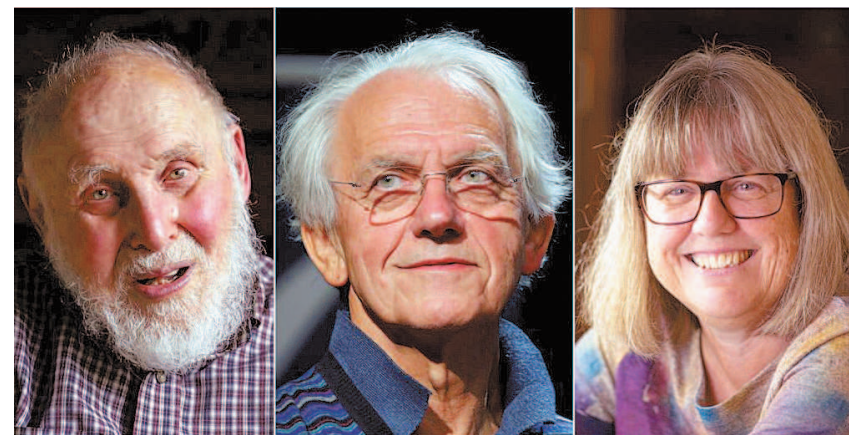

Артур Эшкин, Жерар Муру и Донна Стрикленд

числа «нормальных» частиц, такое состояние называется инверсным, то главным становится вынужденное излучение.

Можно проиллюстрировать эту ситуацию таким «житейским» примером. Когда в большой ярусной аудитории число студентов меньше числа мест, то характер заполнения этой аудитории может быть различным. Нормальное заполнение (распределение по ярусам) это большая плотность студентов в

ной оболочки). Такое излучение Эйнштейн назвал спонтанным (самопроизвольным). Колебания электрического и магнитного поля в каждом кванте этого излучения совершенно не согласованы у разных частиц ни по фазе, ни по направлению. Физики называют такие источники излучения некогерентными.

Но для того чтобы объяснить планковский закон теплового излучения и его гипотезу о квантованности энергии колеблющихся частиц вещества, необходимо предположить, как заявил Эйнштейн, наличие еще одного вида излучения, плотность вероятности которого пропорциональна плотности энергии уже имеющегося излучения такой же частоты, как бы заставляющего, вынуждающего частицу излучить. Эту часть излучения Эйнштейн назвал стимулированным (вынужденным) излучением. У всех квантов такого излучения характер колебания полей совершенно одинаков - оно согласованное, когерентное.

В обычном (равновесном) состоянии вещества доля такого согласованного излучения мала, основное излучение - самопроизвольное. При этом большое число возбужденных частиц успевает вернуться в нормальное состояние и число частиц в возбужденном состоянии всегда меньше числа «нормальных» частиц. Такое распределение частиц по энергиям было установлено еще Больцманом как следствие законов термодинамики в применении к системам частиц и поэтому носит его имя. Но если число возбужденных частиц по каким-то причинам становится больше нижних ярусах и меньшая в верхних. Но допустим, что прошел слух о замене привычного студентам профессора, хорошо читающего лекции и при этом обращающего внимание на усердие студентов, неизвестным ассистентом. И студенты тогда дружно занимают верхние ряды в аудитории, собираясь готовиться к очередной контрольной работе или просто отдохнуть со своим смартфоном. Это - инверсное, не нормальное распределение студентов. Но вдруг слух не оправдался, и в аудиторию входит их профессор. Тогда студенты начинают быстро перемещаться вниз. Это перемещение стимулировано первыми перемещающимися студентами и, глядя друг на друга (согласованно), они восстанавливают нормальное распределение по рядам.

Эйнштейн не развивал идею о том, как можно получить инверсное состояние вещества. В то время его больше всего интересовала теория тяготения (общая теория относительности), и он готовился к ее экспериментальному подтверждению.

В 1939 году советский физик В.А.Фабрикант на опыте показал наличие небольшой примеси вынужденного излучения при обычном равновесном состоянии вещества. В 1951 году он разработал принцип усиления вынужденного излучения средой с инверсной заселенностью энергетических состояний (уровней). Это был принцип двух параллельных зеркал, между которыми вынужденное излучение лавинно усиливается в направлении, перпендикулярном плоскостям этих зеркал. В этом и заключается смысл слова «усилитель» в названиях лазера и мазера (вторая буква $a$ 
названий соответствует английскому acceleration). Лазерный луч вырывается из среды между зеркалами за счет полупрозрачности одного из зеркал или с помощью других устройств.

Заслуга Таунса, Басова и Прохорова состоит в том, что они разработали методы создания среды с инверсной заселенностью уровней. Басов и Прохоров осуществили способ усиления микроволнового радио-излучения и назвали эти устройства мазерами (первая буква $м$ названия - от microwave). Только с помощью мазеров стало возможным осуществление связи между земными и искусственно созданными космическими источниками и приемниками остронаправленного излучения. Таунс и его коллеги сосредоточили свои усилия на разработке усилителей (генераторов) излучения в оптическом диапазоне (первая буква $л$ в слове «лазер» соответствует английскому light). Был создан так называемый рубиновый трехуровневый лазер, в котором инверсное состояние заселенности достигалось за счет безизлучательных переходов между возбужденными атомами алюминия и примеси к нему хрома. Необходимая поддержка возбужденных состояний атомов производилась за счет облучения прозрачного кристалла рубина достаточно мощной спиральной лампой с широким диапазоном излучения. Такой лазер мог работать непрерывно.

Очень быстро стало ясно, что лазер может стать исключительно мощным и точным техническим инструментом. Концентрация энергии в узком лазерном луче создает сильное световое давление. Прежде всего это могло быть использовано в прецизионной обработке металлов - резке, сварке и тому подобное. Но для этого нужно было повышать мощность луча. Препятствиями этому у непрерывных лазеров стали перегрев излучающей среды и разрушение световым давлением отражающих зеркал. Поэтому мощные лазеры принципиально могли быть только импульсными.

В импульсных лазерах пределом их мощности стало $10^{3}$ Вт, что давало давление, оказываемое лучом на преграду, порядка
$10^{3}-10^{4}$ МПа . Для решения технологических задач этого было уже достаточно. Появилось много лабораторий и фирм, создающих промышленные лазеры. Для применения лазеров в исследовании сверхбыстрых процессов, протекающих в атомах, молекулах, твердых телах и биологических объектах, более важным, чем мощность луча, была как можно меньшая временна́я длительность (и, соответственно, малая протяженность в пространстве) лазерного импульса. Но это неизбежно приводило к увеличению мощности до разрушающих значений. Казалось, что выхода нет.

Но в 1985 году произошел прорыв. Жеpap Mypy (Gérard Mourou) и его ученица Донна Стрикленд (Donna Strickland) изобрели технологию создания чирпированного импульса (chirped pulse amplification).

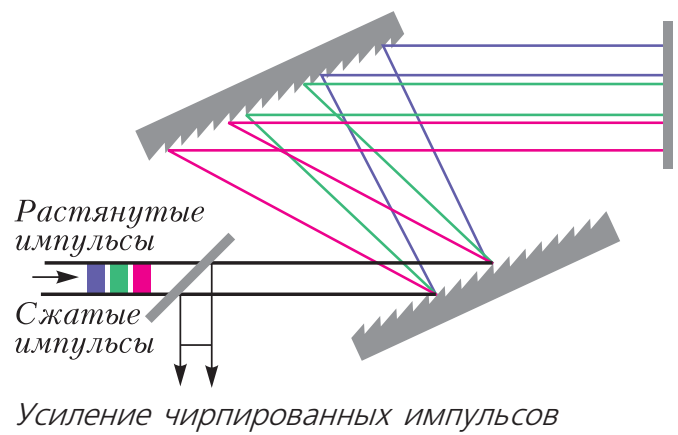

Проще всего переводить слово «чирпирование» как чириканъе, что-то напоминающее птичий щебет. Чирпом еще в 1960 году назвали частотную модуляцию радиоволн, примененную для усиления мощности радаров. Однако перенос этой идеи от радиоволн на оптический диапазон с частотами, в десятки тысяч раз большими, требовал совсем другого решения и в теоретическом плане и в практическом.

Вначале импульс вынужденного лазерного излучения растягивается в тысячи раз по длине и во времени. Соответственно, мощность излучения уменьшается в тысячи раз. Такой импульс можно впустить в лазер, где его мощность будет увеличена до предельно допустимых конструкцией лазера пределов. После этого луч должен поступить в специальное устройство, где 
частота будет увеличена до прежних высоких (световых) значений. Это устройство называется компрессором, поскольку импульс в нем сжимается. При этом, естественно, мощность в импульсе возрастет. Но это уже не будет опасно, поскольку в устройстве импульс будет находиться очень короткое время и не успеет произвести нагревательное и разрушительное действие.

Вот только как растягивать и сжимать импульс? Первой идеей было использовать дисперсию. Ведь это только приближенно можно считать лазерный луч монохроматическим. На самом деле даже при вынужденном излучении всегда существует некий набор длин волн (естественная ширина спектральной линии). В квантовом представлении это означает, что кванты вынужденного излучения все-таки чутьчуть разные по энергии. Следовательно, дисперсия должна иметь место. В веществе импульс излучения будет расширяться по длине и во времени.

В качестве дисперсионных устройств Муру и Стрикленд вначале использовали оптические волокна как с нормальной, так и с аномальной дисперсией, которые могли как удлинять, так и укорачивать импульс. Но длина этого волокна, способного на необходимые растяжения и сжатия, в первых опытах достигала полутора километров. Получить такой оптический «путепровод» как раз стало возможным благодаря замечательным работам англо-американо-китайского инженерафизика Чарльза Као (1/2 Нобелевской премии по физике 2009 года «за новаторские достижения в области передачи света по волокнам для оптической связи»), в прошлом году скончавшегося в 85-летнем возрасте. Результатом его работ стало появление оптических волокон, способных передавать информацию почти без затухания на десятки километров.

Хотя принципиально задача чирпирования световых импульсов была решена, использование приборов таких габаритов не допускало их применения в научных лабораториях. И Муру и Стрикленд, уже после опубликования своей статьи в 1985 году, заменяют дисперсию дифракцией. Обычно дифракционная решетка расширяет импульс, а особым способом изготовленная решетка может, наоборот, сужать его, служить компрессором. Сжатие импульса во времени удалось сделать до величины $10^{-18}$ с (аттосекунды).

Так родилась «аттосекундная физика» изучения поведения отдельных электронов в атомах, молекулах и в твердом теле. Высокая мощность излучения и, соответственно, сверхвысокое световое давление сделали такие лазеры инструментом создания (пока в микромасштабах) экстремальных плазменных состояний вещества огромной плотности, когда, например, диэлектрики становятся проводниками. Такая плазма осуществляется во Вселенной внутри звезд и других космических объектов. Появилась возможность воспроизводить космические состояния в земной лаборатории.

«Космическое» значение таких лазеров проявилось и в задаче очистки околоземных спутниковых орбит от космического мусора. Мощный лазер может сбить мусор с орбиты и заставить его двигаться к земной поверхности, где он будет благополучно сгорать.

Мощные лазеры используются и для создания ускорителей заряженных частиц

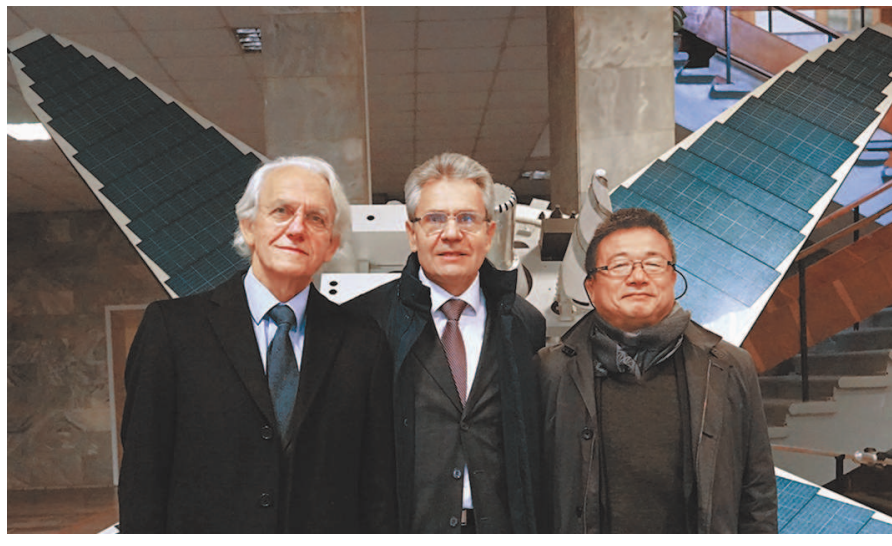

Жерар Муру, Александр Сергеев и Тоси Эбисудзаки на фоне спутника с мощным лазером для уборки космического мусора 
нового типа - так называемых драйверных ускорителей. Мощный короткий лазерный импульс дифференцирует плазму на более легкую (электронную) и более тяжелую (ионную) части. Между ними возникает электрическое поле с огромной напряженностью $10^{21} \mathrm{~B} /$ м , даже большей, чем внутри атома. Это поле представляет собой как бы хвост, кильватер самого импульса. Уже созданы ускорители электронов до энергии 4,2 ГэВ длиной всего лишь в 15 см, работающие по этому принципу. А в качестве режущего инструмента как в технологиях, так и в медицине (хирургии) сегодня применяются только аттосекундные лазеры. Понятно и оборонное значение такого лазера.

Теперь стало ясно огромное значение изобретения Муру и Стрикленд, увенчанное Нобелевской премией 2018 года «за метод генерации высокоинтенсивных ультракоротких оптических импульсов». Точнее, это была только половина Нобелевской премии. Другая половина была присуждена Артуру Эшкину (Arthur Ashkin) «за изобретение оптических пинцетов и их применение в биологических системах». Она стала второй премией, присужденной за необычное применение давления света, оказываемого лазерным лучом.

После создания лазеров Эшкин стал заниматься воздействием лазерного луча на микроскопические объекты, где не нужно большой мощности излучения. Вскоре он обнаружил необычное на первый взгляд явление - давление света смещало микрочастицы не по направлению луча, а в боковом направлении к середине этого луча. Каким бы узким с макроскопических позиций ни был лазерный луч, дифракция обязательно приводит к перераспределению интенсивности излучения по ширине луча. По его оси образуется нечто вроде центрального максимума, а интенсивность по краям луча в несколько десятков раз меньше. Это немного напоминает картину дифракции света на щели. Возникает градиент напряженности электрического поля, направленный от боковой поверхности луча к его оси. На частицы вещества или даже на отдельные молекулы, которые в первом приближении можно считать электрическими диполями, действует боковая (градиентная) сила, перемещающая их к оси луча. Она прижимает частицы к оси, где они находятся в равновесном положении. Особенно устойчиво это положение, когда луч лазера в этом месте сужается, фокусируется сильной линзой. Отрезок луча представляется уже не цилиндром, а усеченным конусом. В этом случае равнодействующая градиентных сил имеет осевое направление и может уравновесить давление света, оказываемое лучом на поверхность микрообъекта. Возникает идеальная лазерная ловушка с устойчивым положением объекта в одной точке.

Имея в распоряжении самые первые маломощные лазеры, Эшкин исследовал поведение объектов, где легко можно было осуществить ловушки. Это были пластмассовые шарики микронных размеров. С увеличением мощности лазеров он исследовал поведение все более мелких частиц. Вначале он совсем не думал об исследовании биологических объектов. Перейти к ним помог случай. В лаборатории росли комнатные цветы, листья которых были поражены мозаичным вирусом. Он часто поражает листья и в подмосковных садах, особенно листья черной смородины и флоксов. На листьях появляется как бы налет мельчайшей пудры различных цветов. Эшкин изучил этот порошок под микроскопом и убедился, что вирусные шарики имели размер всего лишь несколько нанометров. Возможно, это были самые маленькие микрообъекты, которые Эшкин мог иметь в это время. Но они были настолько малы, что микроскопы не могли заметить их передвижение в лазерном луче. В какой-то момент времени на вирусы стали нападать более крупные биологические объекты - бактерии, питавшиеся этими вирусами. Вот их перемещение Эшкин и стал изучать. Правда для этого ему пришлось заменить лазер с зеленой длиной волны на инфракрасный лазер. Зеленый свет губительно действовал на бактерии, а вот в инфракрасном освещении они превосходно себя чувствовали и, находясь дли- 
Copepa, закрепленная в микропипетке

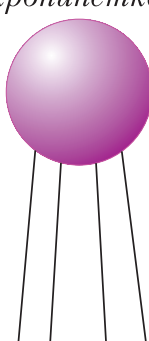

Использование с РНК-полимеразы

тельное время в ловушках, даже были способны к размножению.

Лазерная ловушка Эшкина скоро стала называться оптическим пинцетом (optical twizers), поскольку микрообъекты можно было перемещать в пространстве вместе с перемещением лазерного луча. В 1986 году пинцет был окончательно сконструирован как установка, включающая лазер и микроскопы. Сегодня трудно представить серьезную биологическую лабораторию без оптического пинцета. За прошедшие 30 лет он стал, конечно, более усовершенствованным, удобным в работе и более дешевым. Использованием лазерной ловушки в атомной физике сам Эшкин не занимался. Это стало предметом исследований группы его учеников, выделившихся в самостоятельную лабораторию. В 1997 году Стивен Чу, Клод Коэн-Таннуджи и Уильям Филипс стали нобелевскими лауреатами «за создание методов охлаждения и улавливания атомов лазерным лучом». Создателя лазерного пинцета среди них не было.

И вот в прошлом году Нобелевский комитет осуществил похвальную справедливость, и нобелевским лауреатом «за пинцет» стал, наконец, его первооткрыватель. При этом он стал и самым «возрастным» лауреатом - ему исполнилось 96 лет. Именно биологическая направленность открытия Эшкина отмечается в обосновании этой премии.

А применение пинцета в атомной физике дало замечательные результаты. В 2017 году с помощью микроскопа с сильным разрешением удалось зафиксировать сбли-
Пучок света

Сфера

в лазерном пинцете

$\rightarrow$

изучения структуры менение пинцета. Одновременно используя тысячи лазерных ловушек, в медицине стало возможным создать 3d-зображение группы клеток и отделить здоровые клетки от инфицированных, например для получения более эффективных и безопасных лекарств.

И в заключение несколько слов о лауреатах 2018 года.

Артур Эшкин родился в 1922 году в Нью-Йорке в семье одесского эмигранта Исидора Ашкенази, дантиста по профессии, покинувшего Россию в 1909 году. Артур Эшкин, как и его старший брат, хотел стать физиком. Война прервала его учебу. Он служил в инженерных войсках, занимался совершенствованием радаров. А брат его, уже ставший физиком, работал в Лос-Аламосе, ядерном центре США. После окончания учебы и защиты докторской диссертации Артур Эшкин стал работать в Лаборатории Белла, американском центре радиоэлектроники, где как раз в это время и появились первые квантовые генераторы. Вскоре он возглавил лазерный отдел лаборатории. После создания лазерных ловушек (лазерного пинцета) он руководил усовершенствованием этого своего изобретения. Выйдя на пенсию в 70 лет, он продолжал работу, создав в подвале своего дома собственную лабораторию. Фактически Артур Эшкин был неофициальным шефом работ, развивавших и само изобретение и его внедрение в биологические исследования. И когда ему исполнилось 96 лет, он все-таки получил заслуженную награду и стал самым возрастным нобелевским лауреатом. Пожелаем ему доброго здоровья! 
Жерар Альбер Муру считается американским и французским физиком. Он родился во Франции в 1944 году, в 1967 году закончил университет в Гренобле, а в 1973 году стал доктором философии (по физике) в Парижском университете имени Марии и Пьера Кюри. Интересы французских физиков в то время были сосредоточены на ядерной физике, на мирном использовании ядерной энергии. Франция переходила от электростанций, работавших на немецком каменном угле, к урановым ядерным электростанциям, сегодня почти 80\% электростанций Франции - это ядерные реакторы. И не случайно именно Франция определена местом осуществления крупнейшего международного проекта - созданием экспериментального термоядерного реактора.

Но Муру хотел заниматься лазерами. И он уехал в США, где работал сначала в Рочестерском, а потом в Мичиганском университете, где возглавил работы по сверхмощным и сверхбыстрым импульсным квантовым генераторам. В 1980-е годы он со своими учениками воплотил в жизнь идею чирпирования лазерных импульсов, принесшую ему через 30 лет нобелевскую награду.

В 2004 году во Франции развернулись лазерные исследования и была создана лаборатория прикладной оптики в национальной высшей школе передовых технологий. Муру был приглашен возглавить лабораторию. В России это направление лазерной физики развивалось в нижегородском академическом Институте прикладной физики. И когда в 2001 году институт организовал международную конференцию по лазерной тематике, Муру был приглашен на эту конференцию и стал ее деятельным участником. А после конференции активно работал вместе с сотрудниками института над созданием самой мощной тогда в мире лазерной установ- ки ПЕРЛ. Первые две буквы названия этой установки расшифровываются как петаваттная мощность лазера ( 1 ПВт $\left.=10^{15} \mathrm{BT}\right)$. И это в 300 раз больше, чем мощность всех мировых электростанций! (При этом не следует, конечно, забывать, что эта мощность осуществляется в очень короткое время порядка $10^{-18}$ с. Так что энергия в импульсе всего лишь миллиджоули.)

В 1908 году Муру был избран иностранным членом Российской академии наук. И когда в 2010 году Нижегородский университет при участии Института прикладной физики РАН получил мегагрант российского правительства на создание лаборатории международного уровня «Экстремальные световые поля и их приложения» (ELSALab), Муру в течение 5 лет был ее научным руководителем. Каждый год он четыре месяца проводил в Нижнем Новгороде и успешно справился с поставленной задачей - лаборатория была создана и продолжает успешно работать. В настоящее время на базе этой лаборатории осуществляется масштабный проект Международного центра исследования экстремальных световых полей на базе сверхмощного лазера XCELS. Муру стал председателем международного консультативного совета этого проекта. В 2011 году Правительственная комиссия РФ по высо-

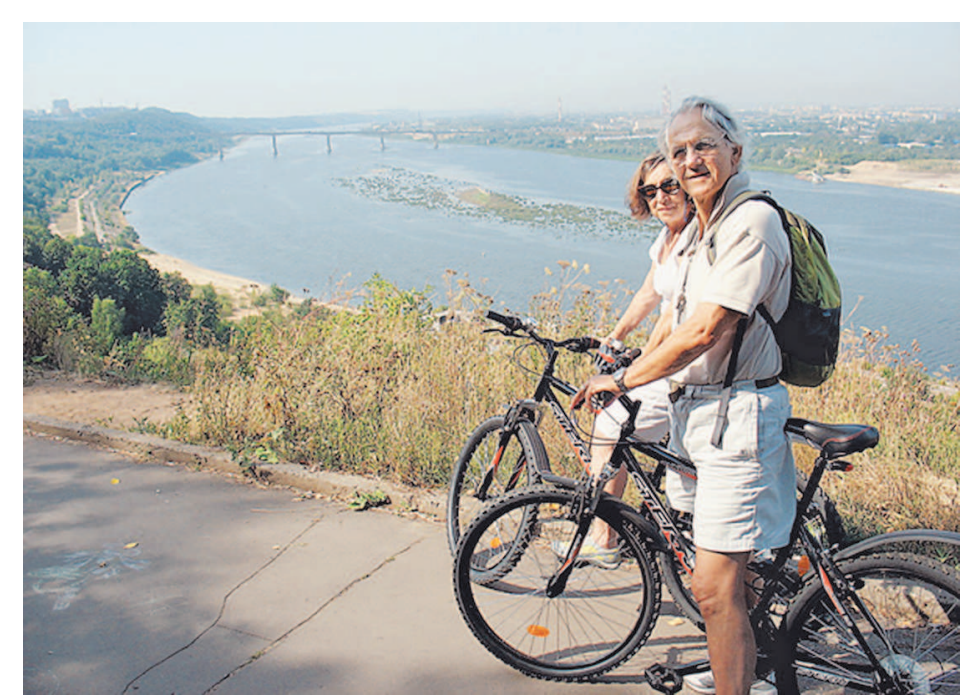

Велосипедные прогулки Жерара Муру по Нижнему Новгороду 
ким технологиям и инновациям включила проект в список из шести проектов типа мегасайенс, которые должны быть реализованы к 2022 году.

В повседневной жизни Муру очень доброжелательный и общительный человек. В Нижнем Новгороде он поразил всех тем, что первым делом приобрел себе и своей жене хорошие велосипеды и стал совершать длинные велопрогулки по городу и его живописным окрестностям. Он хороший пловец и в свои 70 лет переплывает Оку, где она перед впадением в Волгу становится довольно широкой. Его уважают и любят не только молодые коллеги, но и их подрастающие дети. Дружеские отношения вот уже почти 20 лет связывают Жерара Муру с одним из российских ведущих «лазерщиков» Александром Михайловичем Сергеевым, ныне президентом РАН, который своим другом и коллегой был приглашен на церемониальные Нобелевские торжества в Стокгольм в декабре 2018 года. Одно из самых ярких воспоминаний А.М.Сергеева об этих днях - это традиционные нобелевские лекции всех лауреатов. В своем интервью корреспонденту газеты «Московский комсомолец» от 10 января 2019 года президент РАН отмечает, что для него был неожиданным огромный интерес к физике: «Идет череда лекций, три из них в один день - физика, химия, экономика. Часть аудитории в Стокгольмском университете занята приглашенными со всего мира людьми - коллегами, родственниками лауреатов, а вторая часть - это шведская публика, для которой вход в зал был свободным. И что я вижу? На физике с утра - аншлаг, на химии народу поменьше, а на экономике существенно меньше. Вы понимаете, о чем это говорит? Как нация заинтересована в естественных науках! У нас же в России мы, к сожалению, констатируем переполненность залов на различных экономических форумах и заметное снижение интереса к естественным дисциплинам».

Третий Нобелевский лауреат по физике 2018 года Донна Стрикленд стала третьей женщиной-физиком, получившей эту по- четную награду. Первой была Мария Склодовская-Кюри (1903г.), второй физик-теоретик Мария Гёпперт-Майер (1963 г.).

Донна Стрикленд родилась в 1959 году в Канаде и стала физиком после окончания канадского университета Макнестера. Она хотела заниматься мощными лазерами и поехала в США, в Мичиганский университет, в лабораторию Жерара Муру, где стала его аспиранткой. Муру поручил ей важнейший участок экспериментальных работ по чирпированию лазерных импульсов, и уже в 1985 году, на втором году ее аспирантуры, была опубликована совместная статья Муру и Стрикленд, ставшая основополагающей для всех лазерщиков и давшая основание для присуждения Нобелевской премии 2018 года именно им, авторам этой работы. Саму диссертацию на эту тему Стрикленд защитила в 1989 году. Тем самым она установила своеобразный «нобелевский рекорд» присуждения премии за работу, выполненную в аспирантуре.

Донна Стрикленд успешно продолжала работать над увеличением мощности импульсных лазеров в канадском университете Ватерлоо, где она стала президентом Оптического общества. В момент присуждения премии ее должность в университете соответствовала должности доцента (адъюнкт-профессор). Но уже на другой день она стала полным профессором. «Я счастлива и польщена, - сказала она, - что стала одной из трех великих женщин».

Необычайно моложавая и стройная, на церемонии получении знаков нобелевской награды, вручаемых шведским королем Карлом XIV Густавом, она была в строгом, но очень изящном красном платье с одной ниткой жемчуга. Прибывшая в Стокгольм и приглашенная на церемонию вручения наград делегация преподавателей и студентов ее родного университета горячо приветствовала своего нобелевского лауреата, ставшего гордостью и своего университета, и всей Канады. Донна Стрикленд стала десятым Нобелевским лауреатом Канады и вторым канадским лауреатом-физиком. 